\title{
A preliminary epidemiological study of pinworm infection in Thaklong Municipal Early Childhood Development Center and Rangsit Babies' Home, Pathum Thani, Thailand
}

\author{
Aree Taylor ${ }^{* *}$, Prasert Saichua ${ }^{1}$, Pochong Rhongbutsri ${ }^{1}$, Rattana Tiengtip ${ }^{2}$, Sirima Kitvatanachai ${ }^{3}$ \\ and Walter R. J. Taylor ${ }^{4}$
}

\begin{abstract}
Objectives: We investigated the prevalence and risk factors for Enterobius vermicularis in children at the Thaklong Municipal Early Childhood Development Center (TMECDC), and the Rangsit Babies'Home (RBH) in Pathum Thani, Thailand using the Scotch tape method.

Results: 397 children aged 3-6 years were sampled (male =198); 31 (7.8\%) were E. vermicularis positive: 1 (TMECDC) and 30 (RBH). 264/397 (66.50\%) of parents had incomes > 12,000 baht/month and 313/397 (78.84\%) were educated from primary school to college. Univariate analysis identified (i) age 5-6 years, (ii) female sex, (iii) lower education of mother/father, (iv) being a house wife, (v) being a low income family, (vi) being resident in the orphanage, (vii) reporting anorexia and/or fever, and (viii) not washing their bottoms as factors for a positive slide. By logistic regression, education level and age group were independently associated with a positive Scotch tape result. Older children and higher family education had opposing associations with E. vermicularis. Strategies to control pinworm infection should focus on high-risk children in orphanages.
\end{abstract}

Keywords: Pinworm, Scotch tape technique, Socioeconomic status, Thailand

\section{Introduction}

Enterobius vermicularis (pinworm), an intestinal nematode, remains a public health problem in many countries. It tends to be more common in school children in rural areas and in poorer urban areas [1-3]. Studies in school children have found different rates of pinworm infection. In Santiago city, Chile, infection rates were $20.9 \%$ [4], $0.62 \%$ in Taiwan [5], 58.88\% in China [6] and, in one orphanage in Iraq, 84.31\% [7].

*Correspondence: tayaree@tu.ac.th

1 Department of Parasitology, Faculty of Medicine, Thammasat University, Khlong Neung, Pathum Thani, Thailand

Full list of author information is available at the end of the article
Enterobius vermicularis has been reported in every part of Thailand, especially in children who live in rural areas $[1,2]$. Epidemiological studies have reported variable rates of this parasite, e.g. in school children in Bang Khun Thian, the rate was $21.57 \%$ [8] and $38.82 \%$ of school children in Samutprakarn province [9]. The infection rate in kindergarten children in Chiang Mai Province was $45.38 \%$ [10] and 50.9\% in kindergarten children in Khon Kaen Province [11]. No pinworm was found in a kindergarten that is used by educated lecturers at one Thai university, Thammasat, in the northern Bangkok conurbation [12]. One study in an orphanage in the same area found a rate of $15.95 \%$ [13]. Three studies from urban slum areas in Thailand report high rates of between 51 
and $65 \%$, in young children $[11,14,15]$, rates higher than the 7\% found in Karen hill tribes of NE Thailand [16].

Compared to other intestinal parasites, transmission of pinworm is limited because their eggs are unable to survive in the environment. The main routes of infection are autoinfection from eggs or larvae deposited on the anus [3], contamination from fomites like bed sheets, pyjamas, door handles, and inhalation of eggs from hands, bed mattresses or dust. As a result, infections tend to be limited to families and individuals in close proximity like nurseries and boarding schools.

Many cases of $E$. vermicularis infection are asymptomatic but when symptomatic, the most common symptoms include intense itching and inflammation of the anal/or vaginal areas. These symptoms may be accompanied by intestinal irritation, mild nausea or vomiting, irritability, and difficulty sleeping. Heavy infections may cause intestinal inflammation, secondary bacterial infection, abdominal pain and appendicitis. In one series of 405 appendicitis patients, 26 (6.3\%) had pinworm [17]; the finding of pinworms in inflamed appendix walls supports the notion that pinworms can cause appendicitis $[18,19]$.

Other deleterious effects of pinworm include secondary bacterial perineal infections, invasion of organs such as vagina, uterus and gall bladder [20]. In small children, pinworm can reduce intestinal absorption of digested food and lead to malnutrition that in turn impedes growth and development.

Treating pinworm infection effectively requires treating all close contacts. Mebendazole is a drug of choice. Personal hygiene is also important for prevention and control such as washing hands before eating, keeping nails short, cleaning sleeping areas and drying mattresses under sunlight in order to destroy parasite eggs.

Several factors are associated with pinworm infection such as age, gender, and behaviour, e.g. biting or sucking fingers, and poor personal hygiene practices, notably scant attention to hand washing. Lower parental socioeconomic status and poorer education are well-described risk factors [8, 9, 21]. Parents may not have sufficient time to take care of their children and may not be aware of the importance of personal hygiene.

Data on the risk factors for pinworm infection in Thailand are limited. We, therefore, conducted a study to ascertain the prevalence and risk factors of pinworm infection and report our results herein. Such data will be useful for targeting control measures.

\section{Main text}

\section{Methods}

The study took place in December 2015 at two centres: the Thaklong Municipal Early Childhood Development
Center (TMECDC), a well-baby clinic, and the Rangsit Babies' Home (RBH), an orphanage, both located in the northern Bangkok conurbation of Pathum Thani province. The TMECDC is located some $2 \mathrm{~km}$ from the Thammasat University (TU) and serves the local paediatric population (age up to 7 years) of the Klong municipality. The RBH is an orphanage, situated some $8 \mathrm{~km}$ from TU; it houses approximately 300 children from 6 months to 7 years of age. Most are either orphans, former street children, caught up in custody battles, or abandoned.

These centres were selected because of their close proximity to TU and represented two different paediatric populations.

The parents of children attending the TMECDC were sent a consent form, questionnaire and a letter explaining the purpose and nature of the study, including that the results would be communicated only to them and that all collected data were confidential. For the children in the $\mathrm{RBH}$, the authorities are their legal guardian so the same information and forms were sent to them and the head of the RBH signed the consent forms. If parents and authorities allowed the child to be recruited into this study, they were to return the signed consent form and the completed questionnaire.

We sampled children once in the morning at both centres using the Scotch-tape technique. Mothers and staff had been told not to wash the child's bottom on the day of sampling. Slides were examined using standard light microscope and $20 \%$ of negative slides were re-examined for quality control. Symptoms (e.g. anal itching, malaise) and risk factors (e.g. household income, parental occupation) were collected using a structured questionnaire.

The Scotch-tape technique $[22,23]$ involves sticking Scotch-tape on to a tube and using this to touch the skin around the anus to pick up eggs. The contents of the tape are then transferred onto a glass slide and examined using standard light microscope. Oval pinworm eggs measure 50-60 $\times 20-30 \mu \mathrm{m}$ and contain an embryo. When children tested positive, the parent or staff were informed of the result and were given an information sheet about pinworm and its prevention.

Because this was a preliminary study, we did not perform a sample size calculation. However, a sample size of 385 would allow us to detect a prevalence rate of $10 \%$ with a precision of $3 \%$. The data from the structured questionnaires were checked for completeness and then double-entered and cleaned using Epidata v4 (http:// www.epidata.dk/). Data were analysed with Stata v6 (Stata Corporation, TX, and USA). The significance of differences in categorical data was examined using Chi square tests or Fisher's exact test, as appropriate. Logistic regression was used to assess the independence of explanatory variables for pinworm infection. 


\section{Results}

207 children from the TMECDC participated in the project. There are 101 males (48.79\%) and 106 females (51.21\%). Table 1 shows that the majority (94.69\%) of children was in the age group of 3-4 years. Parents were educated mostly to secondary level (51.69\%) and worked as company employees $(51.21 \%)$ with monthly incomes exceeding 14,000 baht (48.3\%).

Children from RBH numbered 97; sexes were approximately equal. The majority of children were also in the age group of 3-4 (38.42\%) and 5-6 (32.63\%) years. Parents were educated mostly to college level (63.63\%), none had an undergraduate degree, most were government or state employees whose monthly income exceeded 12,000 baht (Table 1).

The results of microscopic examination of $40 \times$ magnification showed that the appearance of the eggs of the parasite was similar (D), as shown in Fig. 1.

Of a total 397 children, 31 children were infected (7.81\%): one in the TMECDC and 30 in the RBH. Table 2 shows significant relationships (univariate analysis) between infected group and non-infected groups: age, sex, education level, occupation, income, and residing in the orphanage. In addition, anorexia, fever and washing the child's bottom before the examination were also significant factors.

Logistic regression identified a higher educational level as protective against pinworm [odd ratio (OR) 0.189 (95\% CI $0.07-0.51), \mathrm{P}=0.001$ ] but a higher age group was associated with pinworm infection [OR 2.011 (1.0014.04), $\mathrm{P}=0.049$ ].

\section{Discussion}

This study has found that children from the orphanage, a socially disadvantaged group, accounted for the vast majority of pinworm infections. Pinworm infections in our study were associated with a lower family income and higher age.

Enterobius vermicularis infection is still reported in many countries because it occurs often in children who live together in close communities like orphanages and overcrowded households and is transmitted easily in such environments. Several studies from Thailand report high prevalence rates of infection in high density (>50\%) or slum (85\%) areas of urban Bangkok [15], a kindergarten $(>50 \%)$ in Khon Kaen Province [11] but lower rates $(7-15 \%)$ in the Karen hill tribes [16, 24].

This study was performed using the Scotch tape technique, a well know, widely used, easy, safe and reliable technique $[7,25]$. In this study, 31 children were infected with pinworm, just under $8 \%$. However, only one case from the total number of 207 children $(0.50 \%)$ was found
Table 1 Characteristics of study subjects

\begin{tabular}{|c|c|c|c|}
\hline Characteristics & $\begin{array}{l}\text { TMECDC, } \mathrm{n}=207 \\
(\%)\end{array}$ & $\mathrm{RBH}, \mathrm{n}=190(\%)$ & $P$ value \\
\hline \multicolumn{4}{|l|}{ Age group (years) } \\
\hline$\leq 2$ & $11(5.3)$ & $43(22.63)$ & \multirow[t]{4}{*}{0.000} \\
\hline $3-4$ & 196 (94.69) & $73(38.42)$ & \\
\hline $5-6$ & $0(0)$ & $62(32.63)$ & \\
\hline $7-8$ & $0(0)$ & $12(6.32)$ & \\
\hline \multicolumn{4}{|l|}{ Sex } \\
\hline Female & $106(51.21)$ & 93 (48.95) & \multirow[t]{2}{*}{0.653} \\
\hline Male & 101 (48.79) & $97(51.05)$ & \\
\hline \multicolumn{4}{|l|}{ Education } \\
\hline Primary & $8(3.86)$ & $0(0)$ & \multirow[t]{5}{*}{0.000} \\
\hline Secondary & 107 (51.69) & 71 (37.37) & \\
\hline College & $39(18.84)$ & 119 (63.63) & \\
\hline Bachelor & $47(22.71)$ & $0(0)$ & \\
\hline$>$ Bachelor & $6(2.9)$ & $0(0)$ & \\
\hline \multicolumn{4}{|l|}{ Occupation } \\
\hline Housewife & $21(10.14)$ & $26(13.68)$ & \multirow[t]{6}{*}{0.000} \\
\hline $\begin{array}{c}\text { Government } \\
\text { officer/State } \\
\text { employee }\end{array}$ & $19(9.18)$ & 164 (86.32) & \\
\hline Trade/business & $51(24.64)$ & 0 & \\
\hline $\begin{array}{l}\text { Company } \\
\text { employee }\end{array}$ & $106(51.21)$ & 0 & \\
\hline $\begin{array}{l}\text { Labourer/techni- } \\
\text { cian }\end{array}$ & $9(4.35)$ & 0 & \\
\hline Other & $1(0.48)$ & 0 & \\
\hline \multicolumn{4}{|l|}{ Income } \\
\hline$<8000$ baht & $8(3.86)$ & $63(33.16)$ & \multirow[t]{5}{*}{0.000} \\
\hline $8001-10,000$ & $33(15.94)$ & 0 & \\
\hline $10,001-12,000$ & $29(14.01)$ & 0 & \\
\hline $12,001-14,000$ & $37(17.87)$ & $103(54.21)$ & \\
\hline$>14,000$ & $100(48.31)$ & $24(12.63)$ & \\
\hline \multicolumn{4}{|c|}{ History of stool examination } \\
\hline Yes & $3(1.45)$ & 0 & \multirow[t]{2}{*}{0.096} \\
\hline No & $204(98.55)$ & $190(100)$ & \\
\hline \multicolumn{4}{|c|}{ Bottom cleaning before sample collection } \\
\hline Wash & $170(82.13)$ & $36(18.95)$ & \multirow[t]{2}{*}{0.000} \\
\hline Not wash & $37(17.87)$ & $154(81.05)$ & \\
\hline \multicolumn{4}{|l|}{ Eggs found } \\
\hline Yes & $1(0.50)$ & $30(15.80)$ & \multirow[t]{2}{*}{0.00} \\
\hline No & 206 (95.50) & $160(84.20)$ & \\
\hline
\end{tabular}

at the TMECDC and 30 cases (15\%) from the RBH. This $15 \%$ rate is almost identical to the rates (16\%) found at two other orphanages in Bangkok [26] and in rural based Karen children at Mae Chaem, Chiangmai Province [24] and is a little lower than one study (21\%) in Chilean schoolchildren [4]. 


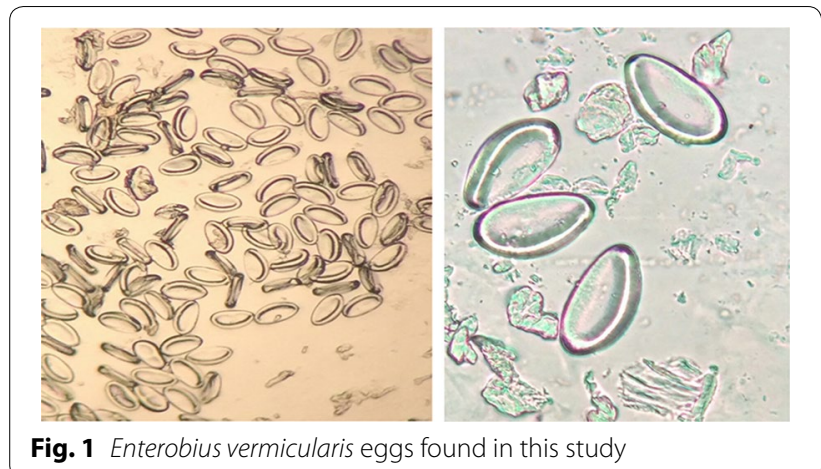

In our study, most infected children (about two-thirds) were older, aged 5-6 years, which is consistent with many other studies [13, 16, 19, 21, 27-32]. However, in one survey in Klong Toey, a crowded slum based community, $85 \%$ of infections were in children aged 8-9 years [15]. We also reconfirmed the importance of lower socioeconomic status as a risk factor for pinworm infection $[8,33$, 34].

We sampled children in the morning at the TMECDC, consistent with other studies, and parents and staff were asked not to wash the child's bottom on the day of sampling. However, most children washed their bottom before sampling and this may explain partly the low rate of detection at the TMECDC. By contrast, we sampled children at the RBH before the children showered, increasing our chances of obtaining a positive sample. In retrospect, it may have been better to have trained the parents to take the Scotch sample at home. Moreover, taking three samples instead of one would have increased our sensitivity, as found in one study in Malaysia [29], and sampling fingernails may also have increased our sensitivity.

The large difference in pinworm detection rates may also be due to greater overcrowding in the orphanage and increased chances of contact between infected and uninfected children. This calls for greater efforts to target control intervention in high-risk groups such as promoting good hygiene for children, cutting nails regularly, and health education for care staff, teachers and parents.

\section{Limitations}

This small study was conducted in two types of institutions looking after children. We only sampled children once and so the sensitivity for detecting pinworm infection was reduced.
Table 2 Factors related to parasitic infection

\begin{tabular}{|c|c|c|c|}
\hline & $\begin{array}{l}\text { Infected } \\
\text { group, } \mathrm{n}=\mathbf{3 1} \\
(\%)\end{array}$ & $\begin{array}{l}\text { Non-infected } \\
\text { group, } n=366 \\
\text { (\%) }\end{array}$ & $P$ value \\
\hline \multicolumn{4}{|l|}{ Age group (years) } \\
\hline$\leq 2$ & $0(0)$ & $54(14.75)$ & \multirow[t]{4}{*}{0.000} \\
\hline $3-4$ & $6(19.35)$ & $263(71.86)$ & \\
\hline $5-6$ & $21(67.74)$ & $41(11.2)$ & \\
\hline $7-8$ & $4(12.9)$ & $8(2.19)$ & \\
\hline \multicolumn{4}{|l|}{ Sex } \\
\hline Female & $22(70.97)$ & $177(48.36)$ & \multirow[t]{2}{*}{0.016} \\
\hline Male & $9(29.04)$ & $189(51.64)$ & \\
\hline \multicolumn{4}{|l|}{ Education } \\
\hline Primary & $0(0)$ & $8(2.19)$ & \multirow[t]{5}{*}{0.003} \\
\hline Secondary & $23(74.19)$ & $155(42.33)$ & \\
\hline College & $8(25.81)$ & $150(41.0)$ & \\
\hline Bachelor & $0(0)$ & $47(12.84)$ & \\
\hline$>$ Bachelor & $0(0)$ & $6(1.64)$ & \\
\hline \multicolumn{4}{|l|}{ Occupation } \\
\hline Housewife & $10(32.26)$ & $37(10.11)$ & \multirow[t]{6}{*}{0.000} \\
\hline $\begin{array}{l}\text { Government officer/ } \\
\text { State employee }\end{array}$ & $20(64.52)$ & $163(44.54)$ & \\
\hline Trade/business & $1(3.22)$ & $50(13.66)$ & \\
\hline Company employee & $0(0)$ & $106(28.96)$ & \\
\hline Labourer/technician & $0(0)$ & $9(2.46)$ & \\
\hline Other & $0(0)$ & $1(0.27)$ & \\
\hline \multicolumn{4}{|l|}{ Income } \\
\hline$<8000$ baht & $23(74.19)$ & $48(13.11)$ & \multirow[t]{5}{*}{0.000} \\
\hline $8001-10,000$ & $1(3.23)$ & $32(8.74)$ & \\
\hline $10,001-12,000$ & $0(0.00)$ & $29(7.92)$ & \\
\hline $12,001-14,000$ & $7(22.58)$ & $133(36.34)$ & \\
\hline$>14,000$ & $0(0.00)$ & $124(33.88)$ & \\
\hline \multicolumn{4}{|l|}{ Stool examination } \\
\hline Yes & $0(0)$ & $3(0.82)$ & \multirow[t]{2}{*}{0.613} \\
\hline No & 31 & $363(99.18)$ & \\
\hline \multicolumn{4}{|l|}{ Crying at night } \\
\hline Yes & $0(0)$ & $35(9.56)$ & \multirow[t]{2}{*}{0.071} \\
\hline No & $31(100)$ & 331 (90.44) & \\
\hline \multicolumn{4}{|l|}{ Bottom itching } \\
\hline Yes & $0(0)$ & $31(8.47)$ & \multirow[t]{2}{*}{0.091} \\
\hline No & $31(100)$ & 335 (91.53) & \\
\hline \multicolumn{4}{|l|}{ Diarrhoea } \\
\hline Yes & $0(0)$ & $36(9.84)$ & \multirow[t]{2}{*}{0.067} \\
\hline No & $31(100)$ & 330 (90.16) & \\
\hline \multicolumn{4}{|l|}{ Anorexia } \\
\hline Yes & $0(0)$ & 68 (18.58) & \multirow[t]{2}{*}{0.008} \\
\hline No & $31(100)$ & $298(81.42)$ & \\
\hline \multicolumn{4}{|l|}{ Fever } \\
\hline Yes & $1(3.23)$ & 98 (26.78) & \multirow[t]{2}{*}{0.004} \\
\hline No & $30(96.77)$ & $268(73.22)$ & \\
\hline
\end{tabular}


Table 2 (continued)

\begin{tabular}{lcll}
\hline & $\begin{array}{l}\text { Infected } \\
\text { group, } \mathbf{n = 3 1} \\
\text { (\%) }\end{array}$ & $\begin{array}{l}\text { Non-infected } \\
\text { group, } \mathbf{n = 3 6 6} \\
\text { (\%) }\end{array}$ & P value \\
\hline $\begin{array}{l}\text { Bottom cleaning } \\
\text { Wash }\end{array}$ & $0(0)$ & $206(56.28)$ & 0.000 \\
Not wash & $31(100)$ & $160(43.72)$ & \\
Places & & & \\
TMECDC & $1(3.23)$ & $206(56.28)$ & 0.000 \\
RBH & $30(96.77)$ & $160(43.72)$ & \\
\hline
\end{tabular}

\section{Abbreviations}

TMCDC: Thaklong Municipal Early Childhood Development Center; RBH: Rangsit Babies' Home.

\section{Authors' contributions}

AT played major roles to the conceptualisation of the study, performed, analysed, interpreted all the data, and contributed to the writing of the manuscript. PS, PR and, SK contributed to the conceptualisation, collected data, contributed to the data analyses and critically revised the manuscript. RT contributed to collect data and worked in a laboratory. WT analysed the data, interpreted the results and critically revised the manuscript. All authors read and approved the final manuscript.

\section{Author details}

1 Department of Parasitology, Faculty of Medicine, Thammasat University, Khlong Neung, Pathum Thani, Thailand. ${ }^{2}$ Laboratory Section, Faculty of Medicine, Thammasat University, Khlong Neung, Pathum Thani, Thailand. ${ }^{3}$ Faculty of Medical Technology, Rangsit University, Khlong Neung, Pathum Thani, Thailand. ${ }^{4}$ Mahidol Oxford Tropical Medicine Research Unit, Bangkok, Thailand.

\section{Acknowledgements}

We wish to thank the staff of Thaklong Municipal Early Childhood Development Center, and Rangsit Babies' Home, Pathum Thani for their co-operation and support this study. We also thank all of the study participants and their families.

\section{Competing interests}

The authors declare that they have no competing interests.

\section{Availability of data and materials}

The datasets of the current study are available from the corresponding author on reasonable request.

\section{Consent for publication}

Not applicable.

\section{Ethics approval and consent to participate}

The study was approved by the Thammasat University Faculty of Medicine Ethics Committee. Written informed consent was obtained from the parents of TMCDC and the authorities of the RBH. The researcher also sent the letter to explain the purpose of the study, including that the results would be communicated only to them and that all collected data were confidential.

\section{Funding}

This study was funded by Thammasat University.

\section{Publisher's Note}

Springer Nature remains neutral with regard to jurisdictional claims in published maps and institutional affiliations.

Received: 29 March 2018 Accepted: 14 August 2018

Published online: 20 August 2018

\section{References}

1. Choi WY, et al. Egg detection rates of Enterobius vermicularis in children. Kisaengchunghak Chapchi. 1987;25(2):181-4.

2. Im Kl, et al. The egg detection rates of Enterobius vermicularis among school children in the various regions. Kisaengchunghak Chapchi. 1986;24(2):205-8

3. Herrstrom HP, et al. Enterobius vermicularis and finger sucking in young Swedish children. Scand J Prim Health Care. 1997;15(3):146-8.

4. Mercado R, Garcia M. Various epidemiological aspects of Enterobius vermicularis infection inpatients served at public outpatient clinics and hospitals from the northern section of Santiago, Chile, 1995. Bol Chil Parasitol. 1996;51(3-4):91-4.

5. Chang TK, et al. Prevalence of Enterobius vermicularis infection among preschool children in kindergartens of Taipei City, Taiwan in 2008. Korean J Parasitol. 2009;47(2):185-7.

6. Oothuman $P$, et al. The prevalence of Enterobius vermicularis amongst primary school children in Pulau Ketam, Selangor-1988. Med J Malaysia. 1989:44(4):312-6.

7. Ban N, AL-Qadhi BN, et al. Enterobiasis and Its Relationship with Enuresis among One of Orphange Care Childrem in Baghdad, Iraq. Iraqi J Sci. 2011;52(3):394-9.

8. Changsap B, et al. Enterobiasis in primary schools in Bang Khun Thian District, Bangkok, Thailand. Southeast Asian J Trop Med Public Health. 2002;33(Suppl 3):72-5.

9. Nithikathkul C, et al. Parasitic infections among Karen in Kanchanaburi Province, western Thailand. Southeast Asian J Trop Med Public Health. 2003;34(Suppl 2):86-9.

10. Tukaew A, et al. Enterobius vermicularis infection among pre-school children in Karen hilltribe villages in Chiang Mai, Thailand. Southeast Asian J Trop Med Public Health. 2002;33(Suppl 3):70-1.

11. Kaewkes $\mathrm{S}$, et al. Enterobiasis in yong school children in Khon Kaen. Parasitol Trop Med Assoc Thai. 1983;6:19-24.

12. Pethleart $A$, et al. Prevalence and risk factors for pinworm infection in the kindergarten of Thammasat University, Thailand. Southeast Asian J Trop Med Public Health. 2010;41(2):306-10.

13. Kitvattanachai $S$, et al. Enterobius vermicularis infection among children living in orphanages in Bangkok and Pathum Thani Province, Thailand. J Trop Med Parasitol. 2000;23(1):28-31.

14. Vajarasthira A, Harinasuta C. The incidence of enterobiasis among children of five school and two hospitals in Bangkok. Ann Trop Med Parasitol. 1960;54:129-31.

15. Tepmongkol M, Suntadwoot CL. Enterobius infection in yong school children in Slum Klongtoei. Siriraj Hosp Gaz. 1980;32:597-600.

16. Nithikathkul C, et al. Malaria and enterobiasis among Karen Long-neck tribe in Mae Hong Son Province. Southeast Asian J Trop Med Public Health. 2003;34(Suppl 2):25-8.

17. Babekir AR, Devi N. Analysis of the pathology of 405 appendices. East Afr Med J. 1990;67(9):599-602.

18. Mogensen K, Pahle E, Kowalski K. Enterobius vermicularis and acute appendicitis. Acta Chir Scand. 1985;151(8):705-7.

19. Wiebe BM. Appendicitis and Enterobius vermicularis. Scand J Gastroenterol. 1991;26(3):336-8.

20. Khan JS, Steele RJ, Stewart D. Enterobius vermicularis infestation of the female genital tract causing generalised peritonitis. Case report. $\mathrm{Br} J$ Obstet Gynaecol. 1981;88(6):681-3.

21. Nithikathkul C, et al. The prevalence of Enterobius vermicularis among primary school students in Samut Prakan Province, Thailand. Southeast Asian J Trop Med Public Health. 2001;32(Suppl 2):133-7.

22. Cabello Rodriguez M. Egg positive rate of Enterobius vermicularis of primary school children in Geoje island. Korean J Parasitol. 2003:41(1):75-7.

23. Kim BJ, Yeon JW, Ock MS. Infection rates of Enterobius vermicularis and Clonorchis sinensis of primary school children in Hamyang-gun, Gyeongsangnam-do (province), Korea. Korean J Parasitol. 2001;39(4):323-5.

24. Saksirisampant $W$, et al. Prevalence of parasitism among students of the Karen hill-tribe in Mae Chame district, Chiang Mai province, Thailand. J Med Assoc Thai. 2004;87(Suppl 2):S278-83.

25. McMahon JN, et al. Enterobius granulomas of the uterus, ovary and pelvic peritoneum. Two case reports. Br J Obstet Gynaecol. 1984;91(3):289-90 
26. Kitvattanachai $S$, et al. Enterobius vermicularis infection among children living in orphanages. J Trop Med Parasitol. 2000;28:28-31.

27. Kang $S$, et al. Egg positive rate of Enterobius vermicularis among preschool children in Cheongju, Chungcheongbuk-do, Korea. Korean J Parasitol. 2006;44(3):247-9.

28. Remm M. Distribution of enterobiasis among nursery school children in SE Estonia and of other helminthiases in Estonia. Parasitol Res. 2006;99(6):729-36.

29. Norhayati $M$, et al. Enterobius vermicularis infection among children aged 1-8 years in a rural area in Malaysia. Southeast Asian J Trop Med Public Health. 1994;25(3):494-7.

30. Waikagul J, et al. A cross-sectional study of intestinal parasitic infections among schoolchildren in Nan Province, Northern Thailand. Southeast Asian J Trop Med Public Health. 2002;33(2):218-23.
31. Mayayo E, et al. Pelvic oxyuriasis. Acta Obstet Gynecol Scand. 1986;65(7):805-6.

32. Little MD, Cuello CJ, D'Alessandro A. Granuloma of the liver due to Enterobius vermicularis. Report of a case. Am J Trop Med Hyg. 1973;22(4):567-9.

33. Changsap $B$, et al. The prevalence of Enterobiasis among children in Khlong Toei Community, Khlong Toei District, Bangkok. Songkla Med J. 2003;21(3):203-8.

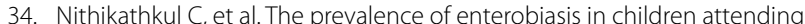
mobile health clinic of Huachiew Chalermprakiet University. Southeast Asian J Trop Med Public Health. 2001;32(Suppl 2):138-42.
Ready to submit your research? Choose BMC and benefit from:

- fast, convenient online submission

- thorough peer review by experienced researchers in your field

- rapid publication on acceptance

- support for research data, including large and complex data types

- gold Open Access which fosters wider collaboration and increased citations

- maximum visibility for your research: over $100 \mathrm{M}$ website views per year

At BMC, research is always in progress.

Learn more biomedcentral.com/submissions 